\title{
La acusación constitucional
}

Víctor García Toma

Abogado por la Universidad San Martín de Porres. Máster en Derecho Constitucional por la Universidad Nacional Federico Villareal.

\section{SUMARI0:}

I. Introducción.

II. La acusación constitucional (juicio 0 antejuicio político) en la Constitución de 1993:

1. La prerrogativa funcional de la acusación constitucional y la inmunidad parlamentaria;

2. Calificación y procedencia de la acusación constitucional (juicio 0 antejuicio político).

III. Las vías de acusación constitucional (juicio 0 antejuicio político):

1. Acusación constitucional en vía de juicio político;

2. Acusación constitucional en vía de antejuicio político.

IV. El procedimiento.

V. Los derechos del procesado.

VI. El efecto de las resoluciones del Congreso.

VII. La acusación constitucional contra el Presidente de la República.

VIII. El procedimiento de remoción constitucional. 


\section{INTRODUCCIÓN}

Este tema deviene en uno de los más complejos e importantes en torno a las atribuciones del Congreso.

A efectos de su mejor estudio haremos una breve descripción de naturaleza histórico-política.

Tal como afirma Javier Valle Riestra [La responsabilidad constitucional del jefe de Estado. Lima: Benítez-Montejo Editores Asociados, 1987]:

"No es ocioso recordar -como lo hace el constitucionalista brasileño Carlos Maximiliano- cómo todos los delitos eran juzgados antiguamente por las asambleas de la tribu. Instituidos más tarde los tribunales, continuaron ciertos delitos de importancia pública o nacional, sometidos al veredictum de todo el cuerpo de ciudadanos o, en todo caso, al consejo de ancianos, al de los jefes de familia o al de los señores feudales. En Atenas, la asamblea popular condenaba al ostracismo al hombre que le parecía peligroso. En Roma, los acusados de cualquier crimen capital debían ser juzgados por el pueblo, reunido en la plaza pública; y entre los germanos del tiempo de Tácito, por el gran consejo".

Empero, como señala Javier Valle Riestra, los antecedentes propiamente dichos se remontan a la Inglaterra del siglo XIV.

Así, durante el reinado de Eduardo III -gobernante entre 1327 y 1377- se estableció la institución del impeachment.

La historia registra que en 1376 se aplicó un impeachment contra el barón William Lotimer (consejero privado y chambelán del rey) Este fue acusado de concertar una voluntad criminal con los comerciantes Richard Lyons y Alice Perrers. En efecto, se le imputó malversación y fraude financiero, al apropiarse de multas que correspondían a la corona, comprar a precio vil las deudas reales a acreedores agobiados por el incumplimiento de los pagos pactados $y$ obtener reembolsos de préstamos ficticios. Tras acreditarse la veracidad de las imputaciones fue encarcelado y multado.

En 1386, el canciller de Inglaterra Michael de la Pole, conde de Suffok fue condenado a prisión por el delito de traición; tras un impeachment en la Cámara de los Lores. El rey Ricardo II ordenó la revocatoria de dicha medida.

Esta institución surgió como consecuencia de que los jueces ordinarios carecían de competencia para procesar y eventualmente sentenciar a los altos dignatarios del reino. Estos, como señala Javier Valle Riestra, eran "personas constituidas en poder, autoridad y dignidad".

Dichos altos dignatarios estaban exentos de responsabilidad de "cualquier naturaleza" $y$, por ende, "sus crímenes con agravantes o atenuantes" quedaban impunes.

En ese contexto, en 1376 se estableció un procedimiento de acusación formal que la Cámara de los Comunes instituía contra los altos funcionarios del Estado ante el Magnum Concilium (el Magnum Concilium estaba integrado por prelados y lores que actuaban como alto tribunal. Posteriormente, devino en la actual Cámara de los Lores).

Con este procedimiento se intentaba promover la formulación de algún tipo de responsabilidad y el establecimiento de un específico tipo de sanción política: la dimisión o separación del cargo por indignidad.

El impeachment puede ser estudiado a través de cuatro períodos, a saber:

\section{Primer período}

Las acusaciones que formulaba la Cámara de los Comunes tenían únicamente una naturaleza de carácter penal. En ese sentido, la imputación planteada contra un alto dignatario del reino debía necesaria e irremisiblemente tener relación con la comisión de un ilícito penal. Ello se produjo aproximadamente a mediados del siglo XVII.

\section{Segundo período}

La acusación se extiende contra los ministros de 
Estado, por faltas graves de carácter político en el ejercicio de su función (por ejemplo, al haber aconsejado o negociado un tratado inconveniente o desventajoso para los intereses del reino).

En ese aspecto, Javier Valle Riestra nos recuerda que bajo el reinado de Carlos II (1660-1685) los ministros debían responder ante la Cámara de los Comunes por la honestidad, justicia y utilidad de su gestión.

\section{Tercer período}

La acusación deviene en un medio de fiscalización absoluta sobre el Órgano Ejecutivo. Las facultades de la Cámara de los Comunes se extienden, al extremo de tener competencia irrestricta para la incriminación y la fijación de penas.

\section{Cuarto período}

A partir de 1782, a consecuencia del famoso caso North, el impeachment quedará en desuso.

En aquel tiempo, el ministro lord Federico North presentó su dimisión al cargo a raíz de un voto de censura formulado por la Cámara de los Comunes, el mismo que era susceptible de llevar consigo, en su contra, la puesta en práctica del impeachment.

La decisión de Federico North implicó, en los hechos, la institucionalización definitiva de la responsabilidad política del Gabinete. Con ello, el impeachment devenía en innecesario. En defecto de este asumían importancia la interpelación y la censura.

No obstante lo expuesto, a raíz del coloniaje impuesto por Inglaterra sobre los habitantes de América del Norte, con el tiempo surgirá en los Estados Unidos la modalidad principal de dicha institución, conocida como"impeachment americano".

Así, aparecerá constitucionalizado en la Constitución del Estado de Virginia (1776).

El primer impeachment fue planteado contra el senador William Blacunt en 1797, el cual con- cluyó declarando que este procedimiento no era aplicable a un miembro del Congreso. No obstante ello, por otra vía se ordenó su destitución. El proceso apuntaba a "despojar a la mala autoridad de su capacidad de acción".

En 1868, el presidente Andrew Johnson fue procesado por haber removido a su secretario de Guerra Edwin Staton, sin el consentimiento del Senado; tal y conforme lo exigía la legislación de la época. El imputado se libró de la sanción por un voto.

En 1999, el presidente Bill Clinton fue absuelto del cargo de perjurio y obstrucción a la justicia, tras la denuncia formulada en ocasión del caso Monica Lewinsky, en ese entonces pasante de la Casa Blanca.

La historia norteamericana registra en total diecisiete procedimientos de impeachment. A la fecha han sido destituidos siete magistrados de la Corte Suprema por cohecho (soborno).

En la versión americana dicho procedimiento alude a la obligación del presidente de la República, el vicepresidente y demás funcionarios civiles en general, de responder a las acusaciones de carácter penal que formule la Cámara de Representantes.

La sanción aplicable consiste en la destitución del cargo y la privación del derecho a obtener y ejercer la función pública. El afectado queda sujeto a la jurisdicción ordinaria para el respectivo proceso penal, de ser el caso.

Dicho procedimiento se instauró en los casos de traición a la patria, cohecho y violación de los deberes políticos.

Este proceso de control que puede desembocar en la suspensión del cargo y la inhabilitación en la función pública, intenta restaurar la dignidad de la función pública.

En la Francia revolucionaria aparece en la modalidad de antejuicio, como una expresión diferenciada más no discriminatoria de la fiscalización de las conductas supuestamente ilícitas, por parte de

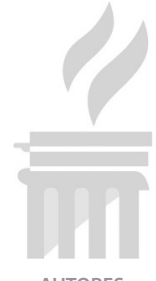
AUTORES
NACIONALES

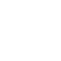


los ministros. Así, en la Constitución de 1791 se estableció que ningún ministro podía ser procesado penalmente por hechos de su administración, sin un previo decreto autoritativo del Parlamento.

Dicho placet no generaba la imposición de sanción alguna, sino la habilitación para el procesamiento ante un órgano jurisdiccional ad hoc.

Cabe aclarar que existe una institución conocida como juicio de residencia, la cual tiene alguna vinculación con el tema.

El juicio de residencia fue un procedimiento de control de origen hispánico, consistente en la obligación de los funcionarios regios de responder por su actuación funcional, bien fuere de oficio o por acción popular.

Fue aplicado por los reyes de España en la etapa colonial. En ese contexto, los virreyes y demás funcionarios administrativos, judiciales y municipales debían dar cuenta de su gestión al finalizar el ejercicio de la función pública. Dicho procedimiento era la cuenta que se tomaba acerca de la conducta funcional.

Este procedimiento fue aplicado por primera vez en 1502, cuando Nicolás Ovando recibió el encargo de residenciar al gobernador de las Indias Francisco de Bobadilla.

Como se recordará, Nicolás Ovando fue el comendador español encargado de restablecer el orden en la isla La Española, llegando al extremo de llevar presos y encadenados hasta la metrópoli, a Cristóbal Colón y sus hermanos.

El juicio de residencia fue establecido para controlar los excesos de poder de las autoridades virreinales en las colonias americanas.

Al respecto, Javier Valle Riestra [ob. cit.] ha comentado que:

"El poder del virrey era inmenso, al extremo de habérsele calificado como el Alter Rex americano, como una verdadera imagen del monarca, y hasta como una encarnación suprema del Estado español".
Sin embargo, dicho funcionario tenía en el juicio de residencia la contingencia que lo limitaba. Al respecto, y como afirma Javier Valle Riestra, la historia ha dejado detallados, dos contrastes en el gobierno de un virrey: de un lado, el ingreso bajo palio y la salida con residencia; y del otro, el cuadro optimista y rosado de las memorias de los virreyes, y los cuadernos o expedientes de residencia.

El procedimiento consistía en que el presidente de la Audiencia invitaba a la presentación de quejas "por agravios, perjuicios, injusticias y serias razones", contra el virrey cesante.

Cada queja era consignada en un cuaderno que era objeto de sustanciación particular. Conocidos y actuados los cargos y descargos respectivos, se procedía a emitir sentencia, la misma que debía ser confirmada por el Consejo de Indias.

La sentencia condenatoria aludía a penas de multa, confiscación de bienes, prisión, destierro e inhabilitación para el ejercicio de cargos públicos.

Entre los virreyes sancionados cabe mencionar a Francisco de Toledo, Francisco de Borja y Aragón -más conocido como el príncipe de Esquilache, Manuel Amat y Juniet, etc.

Este procedimiento se distingue de la vertiente angloamericana anteriormente comentada, en que el imputado de cargos carecía de poder en el momento de la formulación de los mismos. Ergo, se trataba de un ex alto funcionario público. En el primer caso, el control era concurrente; en el segundo, era posterior.

Ahora bien, la institución del impeachment (y a la manera de la impronta de la Constitución francesa de 1791) y el juicio de residencia español, coexistieron a lo largo de buena parte de la historia constitucional peruana. Ello hasta que finalmente el último de los citados desaparecerá con la Constitución de 1860.

Así, el procedimiento de juicio de residencia se mantuvo en el período republicano desde el Reglamento de San Martín, de 1821, pasando por los textos fundamentales de 1823, 1834, 1839 y 1856. 
Entre los principales casos de juicio de residencia republicano, aparece el establecido contra el ex presidente José de la Riva Agüero, en 1825, por supuesta comisión del delito de traición a la patria. Ello a raíz de sus negociaciones con el virrey La Serna, tendientes, según se afirma, a desalojar a Bolívar y sus tropas. Tras una serie de incidentes procesales, el imputado fue absuelto de los cargos.

En 1856 se produjo un juicio de residencia contra el ex presidente Rufino Echenique y sus ministros de Estado, acusados de haber fomentado la desorganización de la República y la ruina de la hacienda pública. Dicho proceso no llegó a concluir.

En cuanto a la institución del impeachment, esta es introducida desde la Constitución de 1823.

Jorge Basadre [Historia de la República del Perú. Lima, 1964] nos recuerda que en 1864, durante el gobierno del general Juan A. Pezet el Congreso de la República llegó a declarar la formación de causa contra todos los miembros del Gabinete conducido por Juan Antonio Ribeyro, por la supuesta falta de traición a la confianza, en actuación al tratamiento de la reivindicación de las islas de Chincha por parte de la armada española. Dicho asunto no llegó a ser resuelto.

Anteriormente, el congresista José Antonio de Lavalle había presentado acusación en 1862, contra el ministro de Gobierno Manuel Morales por dictar un decreto de expatriación y contra el ministro de Guerra Nicolás Freys por otorgar ascensos y elevar remuneraciones a la oficialidad de manera inconstitucional. Ambos pedidos fueron rechazados.

\section{LA ACUSACIÓN CONSTITUCIONAL (JUICIO O ANTEJUICIO POLÍTICO) EN LA CONSTITUCIÓN DE 1993}

De acuerdo al concepto expresado y contenido en la parte inicial del artículo 99 de la Constitución, la acusación constitucional se entiende como un mecanismo procesal de control político destinado a promover, de un lado, la defensa y eficacia de las normas e instituciones previstas en la Constitución, contra el abuso del poder en que pudiesen incurrir los altos funcionarios públicos; y del otro, la intervención del Órgano Judicial -a través de la Corte Suprema- en la investigación, juzgamiento y eventual penalización de determinadas altas autoridades o ex autoridades estatales, cuando pesaren sobre ellas denuncias con razonabilidad jurídica de perpetración de un ilícito penal cometido en el desempeño de la función pública.

Estas altas autoridades son las siguientes:

- El presidente de la República.

- Los congresistas.

- Los ministros de Estado.

- Los miembros del Tribunal Constitucional.

- Los miembros del Consejo Nacional de la Magistratura.

- Los vocales de la Corte Suprema.

- Los fiscales supremos.

- El defensor del pueblo.

- El contralor general.

En este aspecto se presentan graves problemas derivados de la torpe elaboración de la carta fundamental de la República.

A diferencia de la Constitución de 1979 -en donde se presentaba la relación de funcionarios y ex funcionarios con derecho a la acusación constitucional, sin que esto fuese óbice para que una ley determinase al resto de funcionarios beneficiarios de esta prerrogativa-, el texto vigente ha utilizado un listado cerrado. Esto significa que no se puede extender su beneficio a personas distintas de las textualmente enumeradas en el artículo 99.

Pues bien, las mismas organizaciones políticas -Cambio 90 y Nueva Mayoría- que impulsaron el cambio de la Constitución, al poco tiempo de producido este extendieron dicho beneficio a las autoridades del Jurado Nacional de Elecciones mediante el artículo 14 de la Ley Orgánica del Sistema Electoral.

Señálese que la denominada Comisión Del Castillo Gálvez encargada de investigar el caso de los magistrados del Jurado Nacional de Eleccio- 
nes implicados en un vladivideo, determinó que estos no tenían derecho a ese instituto.

Al respecto, en la sentencia del Tribunal Constitucional en el proceso de inconstitucionalidad interpuesto por sesenta y cinco congresistas de la República (Expediente No. 00006-2003-Al/TC) se señaló lo siguiente:

"Asimismo, este Colegiado observa que los miembros del JNE, el jefe de la ONPE y el jefe del RENIEC no cuentan con la prerrogativa del antejuicio político, no obstante ser funcionarios públicos de la mayor importancia en un Estado Democrático de Derecho, teniendo la obligación de 'asegurar que las votaciones traduzcan le expresión auténtica y libre de los ciudadanos; $y$, que los escrutinios sean reflejo exacto y oportuno de la voluntad del elector expresada en las urnas por votación directa' (artículo 176 de la Constitución). Por ello, el Tribunal Constitucional exhorta al Congreso de la República a reformar el artículo 99 de la Constitución, incluyendo a los mencionados funcionarios del sistema electoral entre aqueIlos dignatarios que gozan del privilegio del antejuicio político, o, en su caso, incluyendo una disposición que permita ampliar el privilegio del antejuicio a aquellos funcionarios que la ley establezca, tal como lo hiciera el artículo 183 de la Constitución de 1979".

\section{La prerrogativa funcional de la acusación constitucional y la inmunidad parlamentaria}

Ambos institutos se conectan en la medida en que tienen un objeto sustancialmente análogo: proscribir cualquier forma de procesamiento penal sin que previamente el Congreso de la República hubiere dispuesto el retiro o despojo de la prerrogativa funcional de la inmunidad.

No obstante lo expuesto, existen también diferencias significativas. Al respecto, de conformidad con lo establecido por el Tribunal Constitucional en el caso sesenta y cinco congresistas de la República (Expediente No. 00006-2003-Al/TC), ha quedado establecido que en el levantamiento de la inmunidad parlamentaria el Congreso de la República solo asume un rol estrictamente verificador de la ausencia de contenido político en una demanda; en tanto que en la acusación constitucional se asegura la inexistencia de un probable abuso o exceso en el ejercicio del poder; en cuyo caso se procede a la sanción política o la intervención del Poder Judicial, según sea el caso (juicio o antejuicio político).

Asimismo, plantea diferencias de orden formal y material, a saber:

\section{Diferencias de orden formal}

Todos los funcionarios que gozan de la garantía institucional de la inmunidad (congresistas, defensor del pueblo y miembros del Tribunal Constitucional) tienen además acceso a la prerrogativa de la Acusación Constitucional.

En cambio, no todos los titulares de la prerrogativa de la Acusación Constitucional tienen acceso a la garantía de la inmunidad (ministros de Estado, miembros del Consejo Nacional de la Magistratura, vocales de Corte Suprema, fiscales supremos y contralor general).

\section{Diferencias de orden material}

La garantía de la inmunidad opera desde la elección en el cargo hasta un mes después de haber cesado en él.

La prerrogativa de la acusación constitucional opera hasta cinco años después de haber cesado en el cargo.

En el orden formal se acredita que conforme a lo establecido en los artículos 99, 162 y 201 de la Constitución existen algunos altos funcionarios públicos que acumulativamente gozan del privilegio de la inmunidad y del derecho a no ser procesados sin el previo tamiz autoritativo que surge de la acusación constitucional; en cambio existen otros que gozando del instituto de la acusación constitucional carecen de la prerrogativa de la inmunidad.

Dicha consideración es aplicable al caso del presidente de la República, los ministros de Estado, los miembros del Consejo Nacional de 
la Magistratura, los vocales de la Corte Suprema y el contralor general; los cuales tienen la prerrogativa del antejuicio político, más carecen de la inmunidad.

De otro lado, mientras la inmunidad parlamentaria tiene vigencia desde que la persona es elegida a un alto cargo público y -por interpretación designada defensor del pueblo o miembro del Tribunal Constitucional- hasta un mes después de haber cesado en el cargo; en cambio la prerrogativa funcional del antejuicio permanece vigente hasta 5 años después de haber cesado en el cargo.

En el orden material, en tanto que en el procedimiento para el levantamiento de la inmunidad el Congreso de la República no asume un rol acusatorio, sino, estrictamente verificador de la ausencia de contenido político en la imputación. (Aquí la actividad parlamentaria no tiene como objetivo acreditar la responsabilidad penal del imputado, sino, tan solo, descartar los móviles políticos que pudieren encontrarse encubiertos en una denuncia de "mera apariencia penal").

En cambio en la acusación constitucional (versión antejuicio político) la actividad parlamentaria se centra en investigar y eventualmente hasta acusar constitucionalmente; dejar sin efecto la prerrogativa de la inmunidad; suspender el ejercicio de la función; y, poner al afectado a disposición de la jurisdicción penal correspondiente.

\section{Calificación y procedencia de la acusación constitucional (juicio o antejuicio político)}

A raíz del caso Guillermo Rey Terry, Delia Revoredo Marsano de Mur y Manuel Aguirre Roca (Expediente No. 00340-1998-AA/TC) el Tribunal Constitucional ha establecido que conforme a nuestra Constitución, la acusación constitucional podrá ser calificada bajo dos modalidades, a saber:

El antejuicio como procedimiento destinado a determinar la procedencia del juzgamiento penal de altos funcionarios ante el Órgano Judicial, previa habilitación del Congreso de la República.
El juicio político como procedimiento y sanción congresal de los altos funcionarios por infracción de la Constitución.

Cabe señalar que el citado proceso se originó por la supuesta infracción de haber ejercido un control difuso e inaplicado la denominada Ley de Interpretación Auténtica (Ley 26657) que posibilitaba una nueva reelección presidencial del ingeniero Alberto Fujimori Fujimori.

De otro lado, debe señalarse que conforme a lo resuelto por el Tribunal Constitucional en el caso Luis Alberto Sánchez Ángulo (Expediente No. 04118-2004-HC/TC) el procedimiento de acusación solo suspende el plazo de prescripción, ya que superada la situación legal que detuvo el computo del plazo, este se reanuda ipso facto.

De conformidad con lo establecido en el artículo 99 de la Constitución, la acusación constitucional es procedente en las circunstancias siguientes:

Existencia de denuncia constitucional, encontrándose, el funcionario afectado en el ejercicio de su función.

- Existencia de denuncia constitucional contra un ex funcionario, producida esta dentro de un plazo no mayor de cinco años de generado el cese en la función.

Al respecto, Valentín Paniagua Corazao [" ¿Acusación constitucional, antejuicio o juicio político?" En: La Constitución de 1993. Análisis y comentarios. t. Il. Lima: Comisión Andina de Juristas, s.f.] señala que dicho plazo de caducidad para mantener la prerrogativa de la acusación constitucional "es una novedad absoluta, pero igualmente absurda, incongruente con el antejuicio e incluso injusta".

En ese sentido, compartimos su punto de vista, ya que las incriminaciones maliciosas o indebidas, fundadas en actos de venganza o cálculo político, no se eliminan con el transcurso del tiempo, sino que están sujetas a los avatares de la realidad política que vive el país, y a la actuación y grado de presencia de los dirigentes políticos (muchos de ellos, ex autoridades públicas). 
La acusación constitucional es operativa, según lo dispone el artículo 99 de la Constitución, en las hipótesis siguientes:

\section{a) Denuncia constitucional por supuesta comisión de ilícito penal perpetrado en el ejercicio o desempeño de la función}

Dicha denuncia opera contra los agentes estaduales señalados en el artículo 99 de la Constitución, en ocasión de la supuesta comisión de un ilícito penal cometido por aquel que tiene y ejerce una función pública.

Al respecto, en el libro segundo, parte especial, delitos, Título XVII -denominado“Delitos contra la Administración Pública" (artículos 376 y subsiguientes)- del Código Penal (CP), se fija como ilícitos sujetos de perpetración en el ejercicio de la función, los siguientes:

- Abuso de autoridad.

- Omisión, rehusamiento o demora de actos funcionales.

- Requerimiento indebido de la fuerza pública.

- Abandono del cargo.

- Nombramiento o aceptación indebida de cargo público.

- Concusión.

- Colusión.

- Patrocinio ilícito.

- Malversación.

- Retardo injustificado en el pago.

- Corrupción pasiva propia.

- Corrupción pasiva impropia.

- Aprovechamiento ilícito del cargo.

- Corrupción de magistrados.

- Corrupción activa.

- Tráfico de influencia.

- Enriquecimiento ilícito.

\section{b) Denuncia constitucional por supuesta infracción constitucional}

Dicha denuncia opera contra los operadores estaduales señalados en el artículo 99 de la Constitución, en ocasión de la supuesta realización de cualquier acto por acción u omisión que afecte algún precepto constitucional.

En rigor, se trata de actos vulneratorios de la Constitución no tipificados penalmente.

Al respecto, podrían citarse los casos siguientes:

- Expedición de un decreto de urgencia que contenga materia tributaria (artículo 74 de la Constitución).

- Aprobación de operaciones de endeudamiento interno o externo del Estado, fuera del marco de la ley (artículo 75 de la Constitución).

- Aprobación de la Ley Anual de Presupuesto sin partida destinada al servicio de la deuda pública (artículo 78 de la Constitución).

- Aprobación de tributos con fines predeterminados sin que exista solicitud del Órgano Ejecutivo (artículo 79 de la Constitución).

- Aprobación de tributos referidos a beneficios o exoneraciones sin haberse recibido el informe previo del Ministerio de Economía y Finanzas (artículo 79 de la Constitución).

- Desempeño de un parlamentario como miembro de una comisión extraordinaria de carácter internacional, sin la previa autorización del Congreso (artículo 92 de la Constitución).

- Ingreso de las Fuerzas Armadas y de la Policía Nacional en el recinto del Congreso, sin la autorización del presidente del Congreso (artículo 98 de la Constitución).

- Gestión de intereses propios o de terceros, por parte de un ministro, así como ejercicio de actividad lucrativa, o intervención en la dirección o gestión de empresas o asociaciones privadas (artículo 126 de la Constitución).

- Desempeño del encargo de un despacho ministerial, fuera del plazo señalado por la Constitución (artículo 127 de la Constitución).

- Decretamiento del estado de emergencia o del estado de sitio por un plazo indeterminado, o fuera del plazo establecido en la Constitución (artículo 137 de la Constitución). 
- Negación de dimisión en el cargo de ministro, a pesar de haberse aprobado el voto de censura o no haberse obtenido el voto de confianza.

Al respecto, debe tenerse en cuenta el caso Luz Salgado Rubianes y Carmen Lozada de Gamboa (Expediente No. 03593-2006-AA/TC) en donde se estableció una relación enumerativa de las infracciones constitucionales.

\section{c) Denuncia constitucional por supuesta infracción constitucional, adicionalmente tipificada como ilícito penal en la legislación de la materia}

Al respecto, podrían citarse los casos siguientes:

- Negativa de remisión de la Cuenta General de la República dentro del plazo señalado en el artículo 81 de la Constitución (artículo 377 del CP).

- Negativa u omisión de remisión al Congreso, del proyecto de la Ley Anual de Presupuesto, dentro del plazo señalado en el artículo 78 de la Constitución (artículo 377 del CP).

- Negativa u omisión de poner a disposición del Congreso los efectivos de las Fuerzas Armadas y de la Policía Nacional, tal como lo dispone el artículo 98 de la Constitución (artículo 377 del CP).

En los casos de denuncia constitucional por comisión de un ilícito penal debe tenerse en cuenta lo siguiente: Dicho procedimiento se suscita por todo delito que hubiere sido perpetrado en el ejercicio de las funciones. Es decir, aquellos que de alguna manera se vinculan en el quehacer de la actividad funcional.

Por ende, no es necesario la utilización de dicho mecanismo cuando el delito hubiere sido cometido al margen de dichas funciones (tal el caso de un aborto, parricidio, etc.).

En el caso de los delitos comunes basta con la aplicación de la figura del desafuero. Ello implica que el Pleno del Congreso o la Comisión Permanente se limite de encontrarlo pertinente, a autorizar el enjuiciamiento y hasta la privación de la libertad.

\section{LAS VÍAS DE ACUSACIÓN CONSTITUCIONAL (JUICIO O ANTEJUICIO POLÍTICO)}

La acusación constitucional, de conformidad con lo dispuesto en el artículo 100 de la Constitución y su explicación en el campo de la doctrina, tendría una doble vía y cuasi un solo procedimiento, a saber:

- Acusación constitucional en vía de juicio político.

- Acusación constitucional en vía de antejuicio político.

Esta disquisición doctrinaria -a efectos de "entender" la voluntad del legislador constituyente y la de la propia Constitución- se fija en razón de la existencia de los criterios siguientes:

- Determinación del objetivo que se persigue alcanzar con la tramitación de una acusación constitucional.

- Determinación de los actos funcionales materia de procesamiento político a través de la tramitación de una acusación constitucional.

- Determinación de la naturaleza y efectos de la resolución que pone fin al procedimiento de acusación constitucional.

\section{Acusación constitucional en vía de juicio político}

Aquí se trata de valorar políticamente la conducta funcional. Se produce como consecuencia de un acto de rendición de cuenta del acusado, por la supuesta comisión de un "ilícito político", derivada de excesos en el ejercicio de sus atribuciones constitucionales.

En puridad, viabiliza la tramitación de una falta de naturaleza política no asociada con la perpetración de un ilícito penal. Ello implica considerar que la falta es lesiva al sistema político e indigna de quien ejerce una función pública en nombre y representación del pueblo, teniendo como texto "sacro" a la Constitución.

Al respecto, Jorge Santistevan de Noriega [ $\mathrm{La}$ Constitución comentada. t. II. Lima: Gaceta 
Jurídica, 2005] señala que mediante este mecanismo se lleva a cabo una "evaluación de la responsabilidad de un alto funcionario -en sede exclusivamente parlamentaria-con un pronunciamiento final de carácter político destinado a separar del cargo al infractor de la Constitución; el objetivo buscado es proteger al Estado de los malos funcionarios y preservar la confianza pública depositada en ellos, por lo que cumple una función político-punitiva sobre la base de la'razón política'".

Los efectos de la denuncia cesan en el propio Parlamento, ya sea mediante una resolución de desestimamiento o destitución e inhabilitación para el ejercicio de cargos públicos.

La acción congresal importa la defensa de la Constitución y de la dignidad de la investidura política.

El objetivo que se persigue alcanzar consistiría en asegurar la defensa plena de la Constitución, así como en velar por la recta acción política de los altos dignatarios. En relación a estos últimos, se persigue evitar que estos sean inconsecuentes con el juramento de fidelidad y respeto al texto fundamental.

Dicha modalidad de la acusación constitucional establecida en la Constitución de 1993, tiene su antecedente en el artículo 25 de la Constitución de Cádiz de 1812, en donde se estableció como una facultad parlamentaria el "Hacer efectiva la responsabilidad de los secretarios del Despacho y demás empleados públicos".

Los actos funcionales objeto de investigación política radican en el incumplimiento -por acción u omisión- del deber funcional de respeto, cumplimiento y defensa de la Constitución.

La naturaleza y efectos de la resolución que pone fin al procedimiento de acusación constitucional, y, por ende, la actuación del Congreso en el asunto, radican en la emisión de una decisión política sobre la responsabilidad políticojurídica en el ejercicio de la función pública.

Dicha decisión se agota per se en la continuación de la permanencia o destitución del afectado en el cargo y en su habilitación o inhabilitación para ejercer posteriormente una función pública. En este último caso, la sanción político-administrativa de inhabilitación puede extenderse hasta por el lapso de diez años.

Esta resolución afecta exclusivamente la calidad política del funcionario, estableciendo una capitis diminutio para el ejercicio de la función pública. Ello implica una suerte de degradación cívica contra el responsable de una infracción constitucional carente de tipificación penal.

Al respecto, Germán Bidart Campos [ob. cit.] expone que la denominación de juicio político responde a que no se trata de un juicio penal; $y$, que, por ende,"no se persiguen castigos, sino separar del cargo; no juzgar un hecho como delictivo, sino una situación de gobierno como inconveniente para el Estado".

En relación al tema -y distinguiéndolo del antejuicio político- el Tribunal Constitucional en el proceso de inconstitucionalidad interpuesto por sesenta y cinco congresistas de la República (Expediente No. 00006-2003-Al/TC) ha señalado que si bien la función punitivo-jurisdiccional es privativa del Poder Judicial (aquella que puede sancionar sobre la base de la "razón jurídica"), la función política punitiva (aquella que puede sancionar sobre la base de la "razón política") no lo es. Y no podría serlo, pues justamente el principio de separación de poderes es el que garantiza la ausencia de toda valoración política en las decisiones del Poder Judicial.

Asimismo, expuso que "toda falta política en que incurran los funcionarios que componen la estructura orgánica prevista en la Carta Política, compromete peligrosamente el adecuado desenvolvimiento del aparato estatal. En estos casos, la razón del despojo del cargo no tiene origen en la comisión de un delito, sino en la comisión de faltas que aminoran en grado sumo, la confianza depositada en el funcionario, la que debe ir indefectiblemente ligada al cargo que ostenta".

Compartimos la preocupación por el mal uso que podría darse a la aplicación de esta medida 
sancionadora de carácter político-administrativo.

El animus de animadversión, beneficio o conveniencia "política" podría generar deleznables excesos.

En atención a esto, la resolución del Congreso, si bien tiene una naturaleza política, podría ser objeto de un proceso contencioso-administrativo o de una acción de amparo ante el Órgano Judicial, a efectos de que se pudieran corregir excesos que afectaron el debido proceso.

Al respecto, no debe olvidarse que la resolución legislativa que pone fin al procedimiento es un acto administrativo-político revestido de una solemnidad procesal.

Ahora bien, es procedente la existencia de la acusación constitucional en vía de juicio político, en razón de lo siguiente:

En aplicación del principio de interpretación por "argumento a contrario", puede derivarse, del tercer parágrafo del artículo 100 de la Constitución, la existencia de resoluciones carentes de contenido penal. Agréguese a ello la irrazonabilidad de llevar a cabo una acusación constitucional que declarase haber lugar a procesamiento ante el Órgano Judicial respecto de hechos que carecen de tipicidad, es decir, que nuestra legislación penal no considera como delitos.

Sobre este aspecto, Enrique Chirinos Soto [ob. cit.] afirma:

"Hay infracciones de la Constitución que no están tipificadas en el Código Penal. Por eso, el Congreso puede suspender al alto funcionario o inhabilitarlo o destituirlo, sin deducir responsabilidad de tipo penal".

Como se ha señalado, tal situación se estableció por primera vez, en el controvertido y cuestionable caso de los magistrados del Tribunal Constitucional doctores Guillermo Rey Terry, Delia Revoredo Marsano de Mur y Manuel Aguirre Roca.
Así, mediante las Resoluciones Legislativas 00297-CR, 003-97-CR y 004-97-CR el Congreso de la República en ignominioso acto los destituyó por infracción de la Constitución, en aplicación de lo establecido en el primer párrafo del artículo 100 de la Constitución.

El caso mas emblemático a la fecha es el del ingeniero Alberto Fujimori Fujimori quien tras la vacancia presidencial por permanente incapacidad moral (Resolución Legislativa № 08-2000$\mathrm{CR}$ ) fue objeto de un juicio político.

En efecto, el Pleno del Congreso de la República con el informe de la Comisión Investigadora determinó, mediante Resolución 018-2000-CR de fecha 23 de febrero de 2001 la inhabilitación del ingeniero Alberto Fujimori Fujimori, ex presidente de la República, para el ejercicio de toda función pública por el lapso de diez años.

\section{Acusación constitucional en vía de antejuicio político}

Aquí se trata de efectuar una valorización político-jurisdiccional destinada a permitir que se establezca o se desestime el juzgamiento de un alto funcionario público por la supuesta comisión de un delito en el ejercicio de su función, tipificado como tal en la legislación de la materia.

El objetivo que se persigue alcanzar es definir el tipo de intencionalidad subyacente en la formulación de una denuncia constitucional (venganza política, inconducta funcional, etc.); establecer la razonabilidad de los hechos que originan la denuncia; constatar la existencia de tipicidad penal en la supuesta conducta del imputado; etc.

Los actos materia de procesamiento necesariamente tienen que ligarse con el ejercicio de la función y la defensa de los bienes jurídicos tutelados en la legislación penal.

Jorge Santistevan de Noriega [ob. cit.] señala que el antejuicio político es la antesala de un proceso jurisdiccional que involucra la imputación y prueba de responsabilidades penales que si bien son inicialmente valoradas por el 
Congreso, tiene como propósito habilitar la posterior intervención del Poder Judicial para que se avoque al conocimiento de la causa y aplique las sanciones de naturaleza penal, sobre la base de una "razón jurídica".

Los efectos de la denuncia pueden requerir una posterior intervención del Poder Judicial, para la determinación de responsabilidades de naturaleza penal.

Al respecto, el Tribunal Constitucional en el caso sesenta y cinco congresistas de la República (Expediente No. 00006-2003-Al/TC) ha señalado que en el antejuicio político "solo caben formularse acusaciones por las supuestas responsabilidades jurídico-penales (y no políticas) de las funciones estatales citadas en el artículo 99 de la Constitución, ante los supuestos delitos cometidos en el ejercicio de sus funciones. Una vez que el Parlamento ha sometido a investigación la denuncia (que puede provenir de su propio seno) y ha determinado la existencia de suficientes elementos de juicio que, desde su perspectiva, configura la comisión de un delito en el ejercicio de las funciones, actúa como entidad acusadora, dejando sin efecto la prerrogativa funcional del dignatario, suspendiéndolo en el ejercicio de sus funciones, y poniéndolo a disposición de la jurisdicción penal.

De esta forma, en los casos de antejuicio, las funciones del Congreso pueden ser, en cierta medida, asimiladas a las del Ministerio Público (porque acusa), e incluso a las del juez instructor (porque previamente investiga) pero nunca a las del juez decidor (porque nunca sanciona). Y es que la facultad de aplicar sanciones sobre la base de argumentos jurídicos penales es exclusiva del Poder Judicial.

En síntesis, el antejuicio es una prerrogativa funcional de la que gozan determinados funcionarios, con el propósito de que no puedan ser procesados ante la judicatura penal por los delitos cometidos en el ejercicio de sus funciones, sin que medie previamente un procedimiento con las debidas garantías procesales ante el Congreso de la República y la consecuente acusación del propio Órgano Legislativo.
En efecto, el Tribunal Constitucional en el caso del ex ministro del Interior Fernando Rospigliosi Capurro (Expediente No. 04747-2007-HC/TC) ha declarado que le está vedado al Ministerio Público el iniciar investigación fiscal alguna a propósito de aquellos funcionarios o ex funcionarios con derecho al antejuicio, en tanto no exista pronunciamiento estimable por parte del Congreso de la República.

En lo relativo a la naturaleza y efectos de la resolución que pone fin al procedimiento de acusación constitucional, esta resolución ocasiona que el acusado quede suspendido en el ejercicio de la función y que sea sometido a las resultas del proceso judicial llevado de acuerdo al procedimiento especial sobre la materia. De ser absolutoria la resolución congresal, el expediente de acusación constitucional deberá ser archivado y deberá mantenerse la exención de procesamiento judicial.

\section{EL PROCEDIMIENTO}

El tramité de acusación constitucional se encuentra regulado en los artículos 99 y 100 de la Constitución y en el artículo 89 del Reglamento del Congreso de la República.

Este procedimiento puede ser dividido en tres partes, a saber:

\section{Denuncia constitucional: presunción y calificación}

La presentación de una denuncia puede ser hecha por:

- Los congresistas, ya sea de manera individual o colectiva.

- El fiscal de la Nación.

- La persona natural o jurídica que se considere directamente agraviada.

Dicha denuncia debe contener lo siguiente:

- Sumilla.

- Nombre del denunciante y domicilio procesal, de ser el caso.

- Fundamentos de hecho y derecho.

- Documentos que sustenten la denuncia 
o, en su defecto, la indicación del lugar en donde se encuentran.

- Fecha de presentación.

- Firma del denunciante.

- Copia simple del documento oficial de identificación del denunciante, en caso que la denuncia no provenga de un congresista o del fiscal de la Nación.

Cuando la denuncia es presentada por la persona directamente agraviada, esta es puesta a conocimiento de los congresistas a través de los voceros de los grupos parlamentarios, por siete días útiles. En la siguiente sesión del Pleno del Congreso o de la Comisión Permanente se lee una breve sumilla de la referida denuncia. Transcurrido dicho plazo sin que ningún congresista la hubiere hecho suya, la denuncia será enviada a la Comisión de Acusaciones Constitucionales.

La Comisión de Acusaciones Constitucionales evalúa la denuncia puesta en su conocimiento y determina su procedencia de acuerdo con los criterios siguientes:

- Que haya sido formulado por persona capaz por sí o mediante representante debidamente acreditado.

- Que la persona denunciante sea directamente agraviada por los hechos o conductas que se denuncian.

- Que la denuncia haya sido dirigida contra los funcionarios y ex funcionarios comprendidos en el artículo 99 de la Constitución.

Al respecto, el Tribunal Constitucional en el caso Gastón Ortiz Acha (Expediente No. 03760-2004$A A / T C)$ ha señalado que:

"Si bien es cierto constituye un requisito indispensable para ser pasible de la sanción de inhabilitación prevista en el artículo 100 de la Constitución, al ser uno de los funcionarios previstos en el artículo 99 de la Constitución, ello no implica necesariamente, que el acusado deba encontrarse en el ejercicio de sus funciones, sino que los delitos de función y la infracción constitucional que sea materia de acusación, hayan tenido lugar en ocasión de haber ocupado el cargo público".
Es dable advertir que el accionante actuó a favor del ex presidente Alberto Fujimori Fujimori, a efectos que se deje sin efecto la sanción política de inhabilitación impuesta por el Congreso de la República a través de la Resolución Legislativa 018-2000-CR.

Las denuncias constitucionales presentadas por los congresistas y el fiscal de la Nación, así como las declaradas procedentes por la Comisión de Acusaciones Constitucionales, son enviadas a la Comisión Permanente.

\section{La imputación: investigación e informe}

La Comisión Permanente designa con el voto aprobatorio de la mitad más uno de sus miembros presentes, una subcomisión y a su presidente.

Dicha subcomisión tiene un plazo no mayor de quince días útiles para realizar las investigaciones y presentar su informe. Este plazo puede ser prorrogado por la Comisión Permanente por acuerdo de la mayoría legal de sus miembros.

Efectuadas las audiencias correspondientes y actuadas todas las pruebas, la investigación queda expedita para que se emita el informe final respectivo.

Dicho informe final debe ser remitido a la Comisión Permanente. En caso que se propusiese la absolución de los cargos, así como el rechazo o improcedencia de la denuncia, se procede a votar sin debate.

En la hipótesis que la Comisión Permanente desestimase el informe que declaraba improcedente la denuncia o que reemplazaba esta, se procederá a conformar una nueva subcomisión investigadora, la cual se sujetará al plazo y objetivos que determine la Comisión Permanente.

En caso que el informe final propusiese la acusación ante el Pleno del Congreso este se debatirá y se votará.

En la hipótesis que se aprobase el informe acusatorio, la Comisión Permanente nombrará una subcomisión acusadora. Esta será integrada por 
los miembros de la subcomisión investigadora que hubieren hecho suyo el informe $y$, de ser el caso se elegirá adicionalmente a los restantes entre sus integrantes, ello a efectos de que sustente el informe y formule acusación en su nombre ante el Pleno del Congreso.

\section{Juzgamiento: debate y resolución final}

Aprobada la acusación por la Comisión Permanente, el Consejo Directivo fijará la fecha y hora, así como las reglas a ser aplicadas para el debate de la acusación constitucional, otorgándole prioridad en la agenda.

Luego de la sustentación del informe, de la formulación de la acusación constitucional por parte de la subcomisión acusadora y del correspondiente debate, el Pleno debatirá y votará -se encuentran impedidos de hacerlo los miembros de la Comisión Permanente- pronunciándose en el sentido de si ha o no ha lugar a la formación de causa a consecuencia de la acusación.

De conformidad con lo estipulado en el artículo 3 de la Resolución Legislativa del Congreso 030-2003-CR, de fecha 3 de junio de 2004 (expedida en cumplimiento de la Sentencia del Tribunal Constitucional No. 00006-2003-Al/ TC), el Pleno del Congreso debe pronunciarse en el sentido de si ha lugar o no ha lugar a la formación de causa a consecuencia de la acusación. En el primer caso, queda el acusado en suspenso en el ejercicio de sus derechos sujeto a juicio según ley. En el segundo caso, el expediente se archiva.

El acuerdo aprobatorio de una acusación constitucional, por la presunta comisión de delitos en el ejercicio de sus funciones, requiere la votación favorable de la mitad más uno del número legal de miembros del Congreso, sin participación de los integrantes de la Comisión Permanente.

El acuerdo aprobatorio de sanción de suspensión, inhabilitación o destitución por infracción constitucional, se adopta con la votación favorable de los dos tercios del número legal de miembros del Congreso, sin participación de los miembros de la Comisión Permanente, si- guiendo el principio de razonabilidad señalado por la Comisión de Constitución y Reglamento en su informe presentado el 27 de enero de 2004 y aprobado por el Pleno del Congreso el 28 de enero del mismo año. En este caso, la aplicación de la sanción impuesta por el Congreso es inmediata.

Es dable consignar que en el caso Gastón Ortiz Acha (Expediente No. 03760-2004-AA/ TC) el Tribunal Constitucional determinó que la inhabilitación política es una sanción de la misma naturaleza, sujeta al criterio de razonabilidad.

Esta medida punitiva difiere de la inhabilitación penal prevista en el artículo 36 del Código Penal y de la administrativa establecida en el artículo 30 de la Ley de Carrera Administrativa y el artículo 159 del Reglamento de la Ley Marco del Empleo Público. Por ende, tiene alcances y contenidos propios.

Cuando un congresista solicitare -como consecuencia de la existencia de una pluralidad de denunciados- que una acusación sea votada por separado, el presidente del Congreso debe acceder a dicha petición, sin debate alguno.

Los acuerdos del Pleno que ponen fin al procedimiento, deben constar en una Resolución Legislativa.

En relación al ha lugar o no ha lugar a la formación de causas, es pertinente señalar lo siguiente:

\section{a) Ha lugar a formación de causa}

En este caso, el acusado quedará suspendido en el ejercicio de la función, si se encontrare en el desempeño de la misma, y quedara sujeto a juicio penal ante el órgano jurisdiccional, de acuerdo a ley.

La decisión de ha lugar a formación de causa es independiente de la posibilidad de aplicación de la medida de inhabilitación para el ejercicio de la función pública hasta por diez años, o de la medida de destitución del cargo que ocupare 
el acusado (en puridad se trata de medidas de carácter político-administrativo).

En ese sentido, las medidas sancionadoras de carácter político-administrativo estarían únicamente referidas a una determinación de responsabilidades de carácter político, las mismas que surgen del ejercicio de la función.

Por ende, se deja al órgano jurisdiccional la investigación y juzgamiento de la determinación de responsabilidades de naturaleza penal, las mismas que por mandato constitucional corresponden única y exclusivamente al ente judicial.

Es oportuno mencionar que el acuerdo de "Ha lugar a formación de causa" debe constar en una resolución legislativa.

A manera de resumen sobre esta parte, debe reiterarse que el Congreso no juzga conductas delictivas, sino que únicamente se pronuncia en lo relativo a:

- Determinar si la denuncia contiene o carece de intencionalidad política de perjudicar o dañar al funcionario o ex funcionario incriminado. - Apreciar la verosimilitud de los hechos incriminados.

- Establecer la existencia o inexistencia de infracción constitucional en el ejercicio de la función de parte del incriminado; $y$, en caso de existir infracción, si esta se colige como de ilicitud penal, a tenor de lo que disponga la legislación sobre la materia. Igualmente, en los casos en donde no existe infracción constitucional puede establecer la presunta existencia o inexistencia de una conducta funcional tipificada como delictiva.

- Aplicar medidas político-administrativas en los casos de conductas infractorias de la Constitución, sin que estas sanciones impliquen apreciación de responsabilidades de naturaleza penal.

- Habilitar la intervención del órgano jurisdiccional, a efectos de determinar las responsabilidades de carácter penal.

\section{b) No ha lugar a formación de causa}

En este caso la denuncia es archivada. Por ende, no se produce la habilitación al órgano jurisdiccional para el procesamiento judicial.

Dicha denuncia no puede ser objeto de una nueva interposición hasta el siguiente período anual de sesiones, siempre que vaya acompañada de una nueva prueba sustentatoria.

Debe advertirse que durante el lapso de acusación constitucional, la Comisión Permanente o el Pleno del Congreso, según corresponda, pueden solicitar al vocal titular menos antiguo de la Sala Penal de la Corte Suprema de la República, se imponga, cese o modifique algunas de las medidas limitativas de derecho establecidas en el artículo 2 de la Ley 27379. Tal el caso de las incautaciones, apertura e interceptación de documentos privados, libros contables, bienes y correspondencia; embargo u orden de exhibición para disponer o generar bienes que se inscribirán en los Registros Públicos; levantamiento del secreto bancario y de la reserva tributaria; exhibición y remisión de información en poder de instituciones públicas y privadas; allanamiento de inmuebles e inmovilización de bienes muebles y clausura temporal de labores.

Debe advertirse que el Tribunal Constitucional en el caso del ex ministro de Economía Carlos Bologna Behr (Expediente No. 05312-2006-PA/ TC) ha establecido la posibilidad del control constitucional por supuesta transgresión del debido proceso.

\section{LOS DERECHOS DEL PROCESADO}

El artículo 100 de la Constitución señala que durante las diferentes etapas del procedimiento de acusación constitucional el funcionario o ex funcionario tiene el derecho de ser asistido o representado por un abogado defensor.

\section{EL EFECTO DE LAS RESOLUCIONES DEL CONGRESO}

El expediente con la acusación constitucional es enviado al fiscal de la Nación, quien inexorablemente deberá formular la denuncia penal 
correspondiente ante la Corte Suprema en el plazo de cinco días naturales.

El vocal supremo instructor -el magistrado de menor antigüedad de la Segunda Sala Penal de la Corte Suprema- está obligado a abrir la instrucción correspondiente.

La parte in fine del artículo 100 de la Constitución establece textualmente:

"Los términos de la denuncia fiscal y del auto apertorio de instrucción no pueden exceder ni reducir los términos de la acusación del Congreso".

Valentín Paniagua Corazao [ob. cit.] critica esto último señalando que:

"La denuncia es así un rito burocrático que caricaturiza y convierte al fiscal de la Nación en una virtual mesa de partes del Congreso para llegar al vocal supremo en lo Penal".

En igual sentido, la "parametrización" del auto apertorio de instrucción convierte al magistrado de la Corte Suprema en una suerte de "conserje glorificado".

En suma, en ambos casos se menoscaba la majestad de las altísimas atribuciones que la Constitución consagra a instituciones de la jerarquía del Ministerio Público y del Órgano Judicial.

La depredación del criterio judicial para establecer la acreditación de los términos de la formulación de la denuncia penal y del auto apertorio de instrucción, no tiene otra explicación que la presencia viciosa del "síndrome García Pérez".

Al respecto, el Tribunal Constitucional en el caso sesenta y cinco congresistas de la República (Expediente No. 00006-2003-Al/TC) ha señalado lo siguiente:

"Este Tribunal considera que no existen criterios razonables que permitan concluir que la prerrogativa del antejuicio debe dar lugar a algún grado de interferencia de los poderes públicos encargados, por antonomasia, de la persecución e investigación del delito. Por ello, este Colegiado observa con preocupación lo expuesto en el tercer y quinto párrafo del artículo 100 de la Constitución.

\section{[...] El Tribunal Constitucional considera que} las referidas disposiciones son contrarias al aludido principio fundamental sobre lo que se sustenta el Estado Democrático de Derecho: la separación de poderes. Si bien dicho principio no puede negar la mutua colaboración y fiscalización entre los poderes públicos, impone la ausencia de toda interferencia en las funciones esenciales y especializadas que competen a cada una de las instituciones que diagraman la organización del Estado. En tal sentido, en modo alguno puede restringirse la autonomía que corresponde al Ministerio Público en el desenvolvimiento de las funciones que la Constitución le ha conferido en su artículo 159; menos aún puede aceptarse la limitación de los principios de unidad, exclusividad e independencia de la función jurisdiccional (incisos 1 y 2 del artículo 139), lo que desde luego, alcanza también al juez instructor encargado de evaluar la suficiencia de elementos de juicio que justifiquen la apertura de instrucción y de conducir la etapa investigativa del proceso.

Por lo expuesto, el Tribunal Constitucional exhorta al Congreso de la República a realizar la reforma constitucional correspondiente".

El proceso judicial se inicia en primera instancia ante la Segunda Sala Penal de la Corte Suprema, correspondiéndole a la Primera Sala conocer el proceso en vía de apelación.

El cuarto parágrafo del artículo 100 de la Constitución señala confusamente que la sentencia absolutoria de la Corte Suprema devuelve al acusado sus derechos políticos.

En atención a lo anteriormente expuesto, una sentencia absolutoria llevaría a:

- Dejar sin efecto la suspensión en el ejercicio del cargo, quedando por tanto, el acusado, apto 
para reincorporarse a sus funciones, siempre que durante el procedimiento de acusación constitucional y el proceso judicial no hubiere vencido el período de gestión del funcionario juzgado.

- Dejar sin efecto la inhabilitación del ejercicio de la función pública, en caso de que el Congreso la hubiese impuesto.

\section{LA ACUSACIÓN CONSTITUCIONAL CONTRA EL PRESIDENTE DE LA REPÚBLICA}

El absolutismo presidencial se ha ido afirmando en nuestro país desde la Constitución de 1860, en la misma medida en que fueron reduciéndose los mecanismos y procedimientos destinados a hacer efectiva la responsabilidad del primer mandatario de la República.

La Constitución actual fija las siguientes reglas sobre la materia:

a) De conformidad con lo dispuesto en el artículo 117 de la Constitución, en principio, el presidente de la República es "intocable" durante su gestión

En ese sentido, es inaccesible durante el ejercicio de su mandato, de supuestas infracciones constitucionales en su doble vertiente, o de la comisión de ilícitos penales derivados del ejercicio de la función.

Puede interpretarse, en aplicación del principio del argumento a contrario, que el referido artículo permitiría llevar a cabo un procedimiento de acusación constitucional con posterioridad a la conclusión del mandato presidencial, siempre que la denuncia fuese presentada en aquel plazo de cinco años que exige el artículo 99 de la Constitución.

b) De conformidad con lo dispuesto en el artículo 117 de la Constitución, la intocabilidad del presidente se extiende a los casos de comisión de delitos comunes o no funcionales (homicidios, abortos, lesiones, etc.)

No obstante lo expuesto, nosotros consideramos que el Congreso, enfrentado a la gravedad de una supuesta conducta delictiva de ilícito común del presidente de la República, podría optar por la aplicación del procedimiento especial de vacancia.

En ese aspecto, el inciso 2 del artículo 113 de la Constitución, concordantemente, permite la declaratoria de vacancia de la Presidencia de la República por "incapacidad moral".

c) De conformidad con lo dispuesto en el artículo 117 de la Constitución, el presidente de la República solo puede ser acusado, durante su período, por los siguientes delitos:

- Traición a la patria.

- Impedir las elecciones presidenciales, parlamentarias, regionales o municipales.

- Disolver el Congreso, salvo en el caso previsto en el artículo 134 de la Constitución.

- Impedir la reunión o funcionamiento del Congreso, el Jurado Nacional de Elecciones, la Oficina Nacional de Procesos Electorales y el Registro Nacional de Identificación y Estado Civil.

En esta hipótesis, efectuada la acusación constitucional y el proceso judicial ante la Corte Suprema, en caso de que sobre el presidente de la República recayera una sentencia condenatoria sería pasible de destitución del cargo -en puridad, vacancia-, siempre que los resultados del proceso se produjesen dentro del período de su mandato. No está de más advertir que durante el proceso judicial el presidente de la República se encuentra suspendido en el ejercicio de sus funciones.

\section{VIII.EL PROCEDIMIENTO DE REMOCIÓN CONSTITUCIONAL}

La remoción constitucional es entendida como el acto de privación de un cargo de alta responsabilidad funcional en razón de haberse acreditado la comisión de falta grave en el desempeño de la función.

La falta grave es definida como una infracción de carácter político-laboral, o sea, como una infracción consecuencia del ejercicio de la función. 
El procedimiento de remoción constitucional es aplicado única y exclusivamente por el Congreso, en contra de un específico y preciso número de altos funcionarios.

La Constitución reserva la tramitación de este procedimiento a los altos funcionarios públicos siguientes:

- El contralor general (artículo 82).

- Los miembros del Banco Central de Reserva (artículo 86).

- Los miembros del Consejo Nacional de la Magistratura (artículo 157).

- El defensor del pueblo (artículo 161).

La Constitución presenta diferencias en lo relativo a esta materia. Así, tenemos que:

No especifica-como sí lo hace con el resto de los funcionarios anteriormente citadoslas razones en que se fundamentaría la remoción del defensor del pueblo; esto es, no expresa que debe ser consecuencia solo de la comisión de falta grave. En aras de la coherencia, entendemos que la práctica constitucional restringirá el acto de remoción a la causal de falta grave.

- El artículo 99 de la Constitución establece el procedimiento de acusación constitucional contra algunos de los funcionarios arriba citados, vale decir, el contralor general, el defensor del pueblo, los miembros del Consejo Nacional de la Magistratura; y simultáneamente, a través de los artículos 82,157 y 161 , los señala como incursos en el procedimiento de remoción. Apoyándonos en la necesaria sindéresis legislativa, consideramos que para el caso de los citados funcionarios se puede hacer la siguiente disquisición: a) Se debe aplicar el procedimiento de acusación constitucional cuando se trata de una falta grave de naturaleza constitucional o constitucional-penal; b) Se debe aplicar el procedimiento de remoción constitucional cuando se trata de falta grave de cualquier otra naturaleza. La Constitución omite pronunciarse sobre la procedencia o improcedencia de la remoción del superintendente de Banca y Seguros. Añádase que este funcionario no está incurso en el procedimiento de acusación constitucional.

La mayoría oficialista no fijó las reglas atinentes a este procedimiento en el Reglamento del Congreso de la República; empero, a través del artículo 93 del mismo se señala que un futuro instrumento legal regulará el procedimiento de remoción constitucional.

Señala además que dicho procedimiento debe concluir con la expedición de una resolución legislativa.

Entendemos que el procedimiento que se establecerá deberá tener en cuenta los principios que sustentan el debido proceso y la tutela jurisdiccional. 